\title{
A male patient with delirium, seizures and (limbic) encephalitis with bilateral mesial temporal lobe involvement
}

\author{
Um paciente do gênero masculino com delirium e crises convulsivas por encefalite \\ límbica, com comprometimento bilateral dos lobos temporais mesiais
}

Ricardo Krause Martinez de Souzaํ, Ronaldo Pereira Vosgerau², Henry Koiti Sato ${ }^{3}$, Pedro André Kowacs ${ }^{4}$

A 52-year-old male presented with a fortnight history of delirium and partial motor seizures. He had no fever or other systemic or neurological signs, but he showed a mini-mental state examination (MMSE) score of 8/30. Fluid-attenuated inversion recovery (FLAIR) magnetic resonance images (MRI) of the head revealed hyperintense signals in both temporal lobes (Figure). Serologies for herpes simplex virus, varicella zoster virus, toxoplasma, cytomegalovirus, Epstein-barr virus, and HIV were negative, but fluorescent treponemal antibodyabsorption (FTA-Abs) and venereal disease research laboratory (VDRL) (1:32) were reactive. Cerebrospinal fluid (CSF) examination revealed 10 leukocytes $/ \mathrm{mm}^{3}$ (95\% lympho cytes), $77 \mathrm{mg} / \mathrm{dL}$ protein, $75 \mathrm{mg} / \mathrm{dL}$ glucose, and VDRL 1:2. Mesial temporal lesions are commonly associated with herpetic encephalitis ${ }^{1}$ or autoimmune paraneoplastic limbic encephalitis ${ }^{2}$. However, neurosyphilis must also be considered.
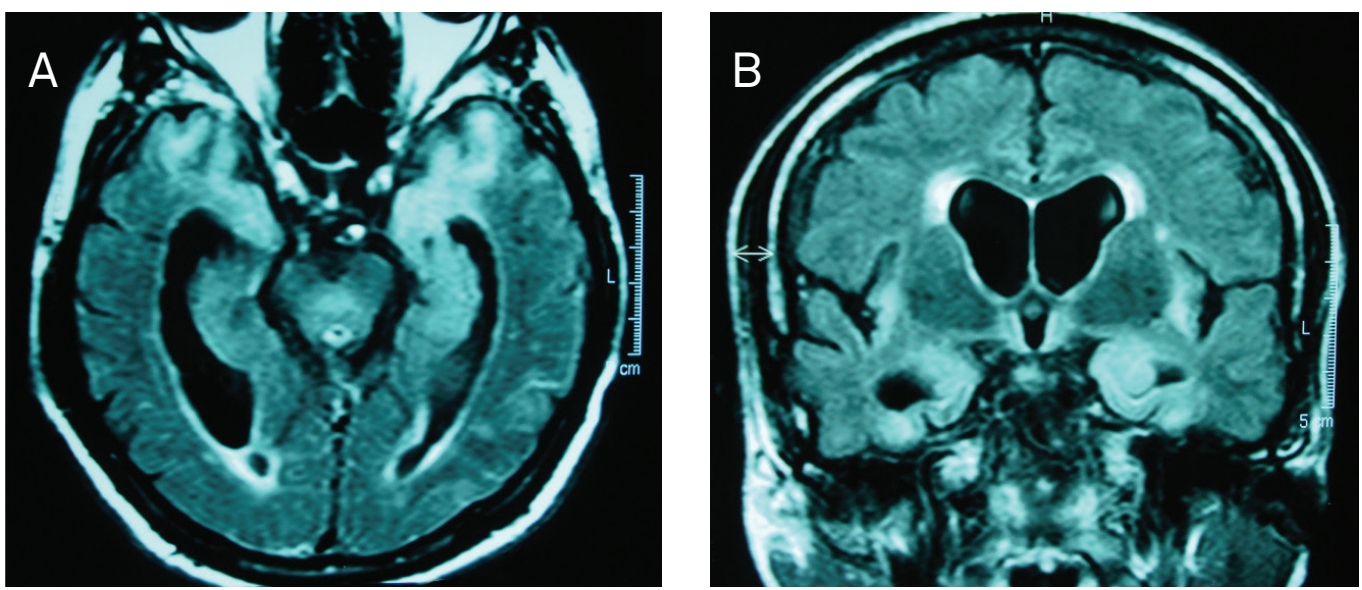

Figure. Fluid-attenuated inversion recovery (FLAIR) axial (A) and coronal (B) magnetic resonance images showing bilateral medial temporal high-signal lesions with associated asymmetric enlargement of the temporal horns of the lateral ventricles. The enlargement is more marked on the right side.

\section{References}

Tien RD, Felsberg GJ, Osumi AK. Herpes virus infections of the CNS: MR findings. AJR Am J Roentgenol 1993;161:167-176.
Gultekin SH, Rosenfeld MR, Voltz R, Eichen J, Posner JB, Dalmau J. Paraneoplastic limbic encephalitis: neurological symptoms, immunological findings and tumour association in 50 patients. Brain 2000;123:1481-1494.

\footnotetext{
${ }^{1}$ Coordenador do Ambulatório de Desordens da Memória e do Comportamento (ADEMEC), Instituto de Neurologia de Curitiba (INC), Curitiba PR, Brazil; ${ }^{2}$ Neurorradiologista do Centro de Tomografia Computadorizada (CETAC), INC, Curitiba PR, Brazil;

${ }^{3}$ Coordenador do Ambulatório de Doenças Desmielinizantes, INC, Curitiba PR, Brazil;

${ }^{4}$ Chefe do Serviço de Neurologia do INC, Curitiba PR, Brazil.

Correspondence: Ricardo Krause Martinez de Souza; Rua Jeremias Maciel Perretto 300; 80210-310 Curitiba PR - Brasil; E-mail: ricardo.neurologia@hotmail.com Conflict of interest: There is no conflict of interest to declare.

Received 24 September 2012; Received in final form 03 December 2012; Accepted 11 December 2012.
} 